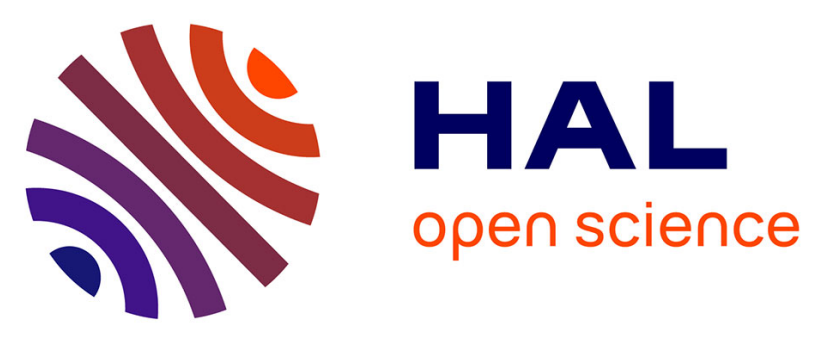

\title{
Valorization of waste cooking oil based biodiesel for biolubricant production in a vertical pulsed column: Energy efficient process approach
}

\author{
Masoud Dehghani Soufi, Seyyed Mohammad Mousavi, Masoud Dehghani
} Soufi, Barat Ghobadian, Seyyed Mohammad Mousavi, Gholamhassan Najafi, Joelle Aubin

\section{To cite this version:}

Masoud Dehghani Soufi, Seyyed Mohammad Mousavi, Masoud Dehghani Soufi, Barat Ghobadian, Seyyed Mohammad Mousavi, et al.. Valorization of waste cooking oil based biodiesel for biolubricant production in a vertical pulsed column: Energy efficient process approach. Energy, 2019, pp.116266. 10.1016/j.energy.2019.116266 . hal-02373133

\section{HAL Id: hal-02373133 \\ https://hal.science/hal-02373133}

Submitted on 22 Nov 2019

HAL is a multi-disciplinary open access archive for the deposit and dissemination of scientific research documents, whether they are published or not. The documents may come from teaching and research institutions in France or abroad, or from public or private research centers.
L'archive ouverte pluridisciplinaire HAL, est destinée au dépôt et à la diffusion de documents scientifiques de niveau recherche, publiés ou non, émanant des établissements d'enseignement et de recherche français ou étrangers, des laboratoires publics ou privés. 


\title{
Valorization of waste cooking oil based biodiesel for
}

\section{biolubricant production in a vertical pulsed column: energy efficient process approach}

\author{
Masoud Dehghani Soufi ${ }^{\mathrm{a}, \mathrm{d}}$, Barat Ghobadian ${ }^{\mathrm{a},{ }^{*}, \text { S. Mohammad Mousavi }}{ }^{\mathrm{b}}$, \\ Gholamhassan Najafia,e , and Joelle Aubin ${ }^{\mathrm{c}}$
}

a Mechanical and Biosystems Engineering Department, Tarbiat Modares University, Jalal Ale Ahmad Highway, Tehran, Iran.

b Chemical Engineering Department, Tarbiat Modares University, Jalal Ale Ahmad Highway, Tehran, Iran.

c Laboratoire de Génie Chimique, Université de Toulouse, CNRS, INPT, UPS, France.

${ }^{\mathrm{d}}$ Department of Agrotechnology, College of Abouraihan, University of Tehran, Tehran, Tehran, Iran.

${ }^{\text {e }}$ Mechanical Engineering Department, Eindhoven University of Technology, Eindhoven, Netherlands.

*Corresponding author email: Ghobadib@modares.ac.ir 


\begin{abstract}
Biolubricants have received growing interest as potential substitutes to conventional environmental pollutant petroleum-based lubricants. Due to their renewability, biodegradability and superior properties compared with mineral lubricants, they can play a significant role in overcoming some of the global challenges such as dependency on petroleum-based products, reduction of energy consumption and environmental pollution. In this study, a vertical pulsed column with tri-orifice baffles was applied to produce the biolubricant trimethylolpropane fatty acid triester from waste cooking oil, which is a cost and environmentally effective feedstock. In addition, response surface methodology was used to optimize the levels of different operating parameters to obtain the highest reaction yield and the lowest power consumption. An optimal reaction yield of $83.3 \%$ and power consumption of $1006 \mathrm{~kW} / \mathrm{m}^{3}$ were obtained with an oscillation frequency of $3.6 \mathrm{~Hz}$, a baffle spacing of $1.45 d_{e}$, a molar ratio of $4: 1$ and a potassium carbonate catalyst loading of $1 \%$.
\end{abstract}

Keywords: pulsed column; biolubricant; waste cooking oil; biodiesel; energy efficient process. 


\section{Introduction}

According to the Global Industry Analysts report [1], the soaring trend of the global demand of lubricants will have reached 10.9 billion gallons by 2017. Non-renewable petroleum-based lubricants currently account for $85-90 \%$ of the global lubricant market [1]. In addition to the need to find renewable and sustainable alternatives for petroleumbased products, these mineral lubricants are extremely dangerous for the environment. One kilogram of mineral lubricant is capable of polluting one million liters of water [2] and $55 \%$ of hazardous lubricants end up in the nature each year worldwide [3]. Global concerns about the future of mineral lubricants, ever-increasing strict environmental regulations and growing awareness on the advantages of using biodegradable lubricants are the main factors driving the lubricant producers to find eco-friendly, sustainable, technically-acceptable and cost efficient alternatives.

Vegetable oils were originally used in the lubrication of machinery and industrial tools before the discovery of petroleum, but then were replaced by mineral lubricants due to their cheaper price and better performance [4]. Vegetable oils have superior physicochemical properties to mineral lubricants including higher viscosity indices, better lubricity leading to lower friction losses, better fuel economy, and higher flash points (leading to increased safety for transportation and storage, as well as lower evaporation rates and therefore lower emissions). However, lower oxidation stability and higher pour point are the main drawbacks for vegetable oils thereby limiting their direct use as lubricants in lubrication systems [5-7]. A variety of methods, namely esterification/transesterification, estolide formation, epoxidation and genetic modification, are used to amalgamate the physicochemical properties of vegetable oils and overcome their deficiencies [8]. Trimethylolpropane fatty acid triester (TFATE) is a 
vegetable oil based polyol ester that is one of the most desired renewable and biodegradable biolubricant base stocks $[9,10]$. The preferred reaction for TFATE synthesis, due to its low cost, as well as high energy efficiency and reaction yield [9], is the transesterification of methyl ester with trimethylolpropane (TMP), which is a costeffective polyhydric alcohol. The synthesis of TFATE from triglyceride is a two-step process, as shown in Fig. 1, comprising the transesterification of the triglycerides with methanol to form methyl ester, followed by the transesterification of methyl ester with TMP.

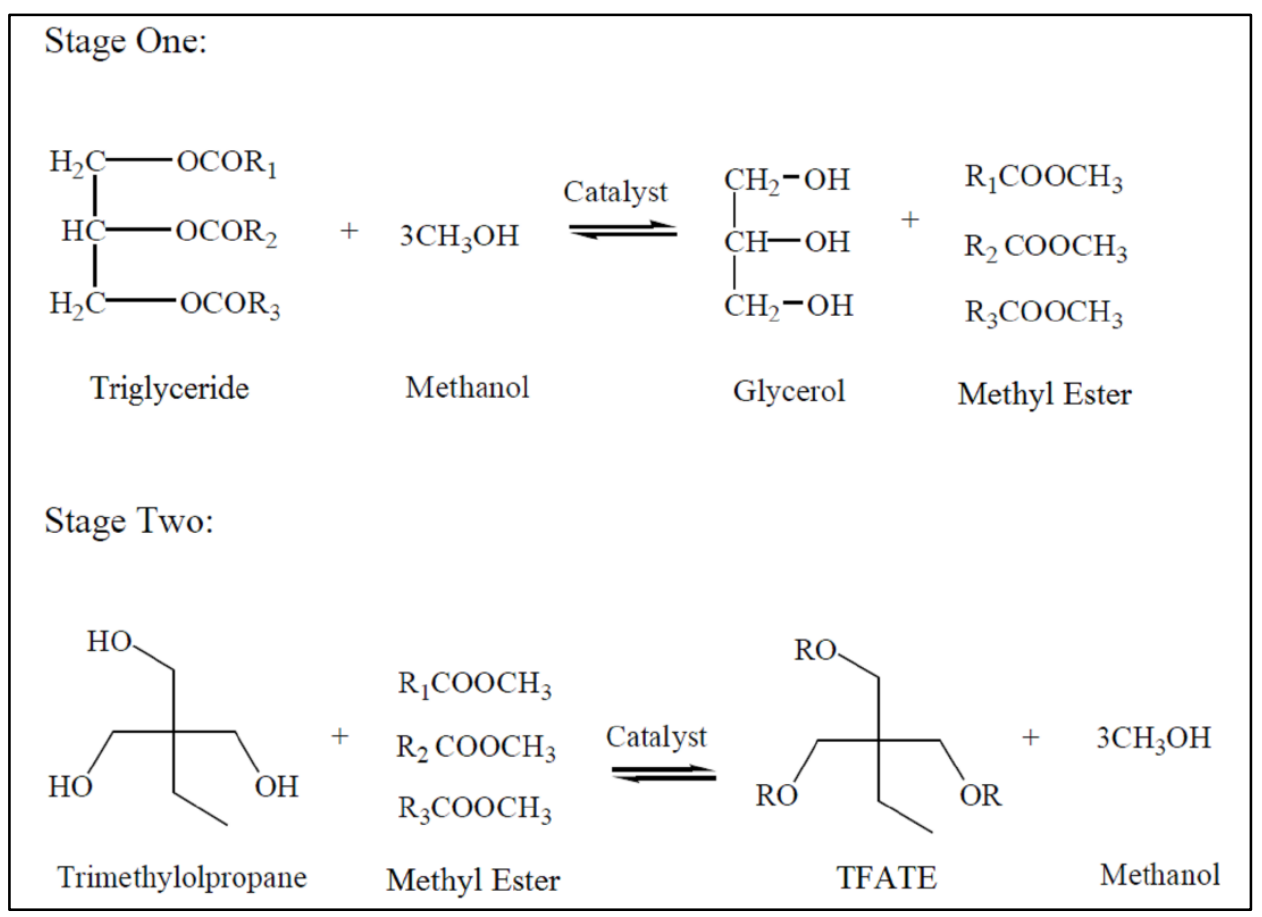

Figure 1: The chemical equations of TFATE synthesis from triglyceride.

Amongst more than 350 oil-bearing crops throughout the world, it has been shown that high oleic vegetable oils (HOVOs) are the most appropriate starting material for biolubricant production [4]. However, the use of virgin vegetable oils as lubricant feedstock can cause some controversial issues including lubricant vs. food/feed competition, greenhouse gas (GHG) emission and land use changes [11]. These issues 
can be overcome by using waste cooking oils (WCO), which are usually two to three times cheaper than virgin vegetable oils and can effectively decrease biolubricant cost $[12]$.

Process intensification is a chemical and process design methodology that can be used to make chemical processes more sustainable, energy-efficient and cost-effective [13]. Recently, a number of process intensification methods have been applied to lower the time and energy consumption of transesterification reactions by intensifying heat and mass transfer, resulting in improved processes and products [14,15]. The vertical pulsed column (VPC) is a type of oscillatory baffled reactors (OBR) which is one means for the intensification of multiphase reactions. OBR applications have increasingly been investigated in a number of different chemical processes such as polymerization [16], crystallization $[17,18]$, biodiesel synthesis $[19,20]$ and ozonation reaction $[21,22]$.

The OBR consists of a tube or column fitted with baffles of various types (e.g. single orifice, helical [23,24], disk and donut [25,26], smooth periodic constriction (SPC) [27] and multi-orifice baffles $[21,28])$. The fluid in the OBR is forced to oscillate by means of a reciprocating piston or diaphragm. As the oscillating flow passes through each of the baffle constrictions, it generates a cycle of vortex formation and dissipation, which results in improved radial mixing in each inter-baffle zone and enhances mass and heat transfer.

Recently, palm oil based biolubricant production in an oscillatory baffled reactor with single orifice baffles has been demonstrated [29]. The results show the effectiveness of the OBR in producing $94.6 \%$ palm oil based biolubricant at $140{ }^{\circ} \mathrm{C}$ in $25 \mathrm{~min}$, which is much shorter than achieved in a stirred batch reactor (approx. 2 hours [30]). Hamid et 
al. [31] investigated the influence of five operating parameters on palm biolubricant production in a pulsed loop reactor. They found that the operating parameters which had the most significant effect on TFATE yield were reaction temperature, vacuum pressure, palm methyl ester to TMP molar ratio, sodium methoxide catalyst loading and the oscillatory speed.

Since energy efficiency of industrial chemical reactors directly affects the final product cost, it is important to understand how the operating conditions and reactor geometry effect reaction yield and power consumption. Only a few studies have focused on the effect geometrical parameters on the performance of non-reactional systems in single orifice baffle OBRs resulting in indications for baffle design, e.g. open baffle area of $20-24 \%$ [32]; and baffle spacing of $1.5 d$ to $1.8 d$ [33,34], where $d$ is the reactor diameter. However, these parameters have never been optimized for chemical reactions with specific optimization methods.

In this study, a vertical pulsed column was used to intensify TFATE production from waste cooking oil. Response surface methodology (RSM) was employed to optimize the TFATE production process in terms of both reaction yield and energy consumption as a function of the operating parameters. Furthermore, RSM was used to perform a statistical analysis of interactions between operating parameters to find the optimum levels of each, enabling maximum reaction yield and minimum energy consumption to be obtained. 


\section{Materials and methods}

\subsection{Materials}

WCO with $<1 \%$ FFA was provided by the Tarbiat Modares University (TMU) restaurant (Tehran, Iran). It was filtrated and preheated at $100{ }^{\circ} \mathrm{C}$ for about $3 \mathrm{~h}$ to eliminate food and water prior to the reaction. Oleic acid $(32.9 \% \mathrm{wt})$ was the dominant fatty acid in the WCO. Other components were palmitic acid $(30.4 \% \mathrm{wt})$, linoleic acid $(21.0 \% \mathrm{wt})$ and small amounts of stearic, linolenic and other fatty acids.

Trimethylolpropane (2-ethyl-2-(hydroxymethyl)-1,3-propanediol), potassium carbonate, methanol, potassium hydroxide and were purchased from Merck. All reagents were of analytical grade.

\subsection{Experimental equipment}

A VPC with tri-orifice baffles with an internal diameter of $0.06 \mathrm{~m}$ and height of $0.55 \mathrm{~m}$ was fabricated in-house based on the geometry provided by Nogueira et al. [35]. The inter-baffle spacing, $l$, was varied between $0.05 \mathrm{~m}$ and $0.10 \mathrm{~m}$, corresponding to $1.4 d_{e}$ and $2.9 d_{e}$, respectively, where $d_{e}$ was calculated through the following equation [36]:

$$
d_{e}=\sqrt{d^{2} / n}
$$



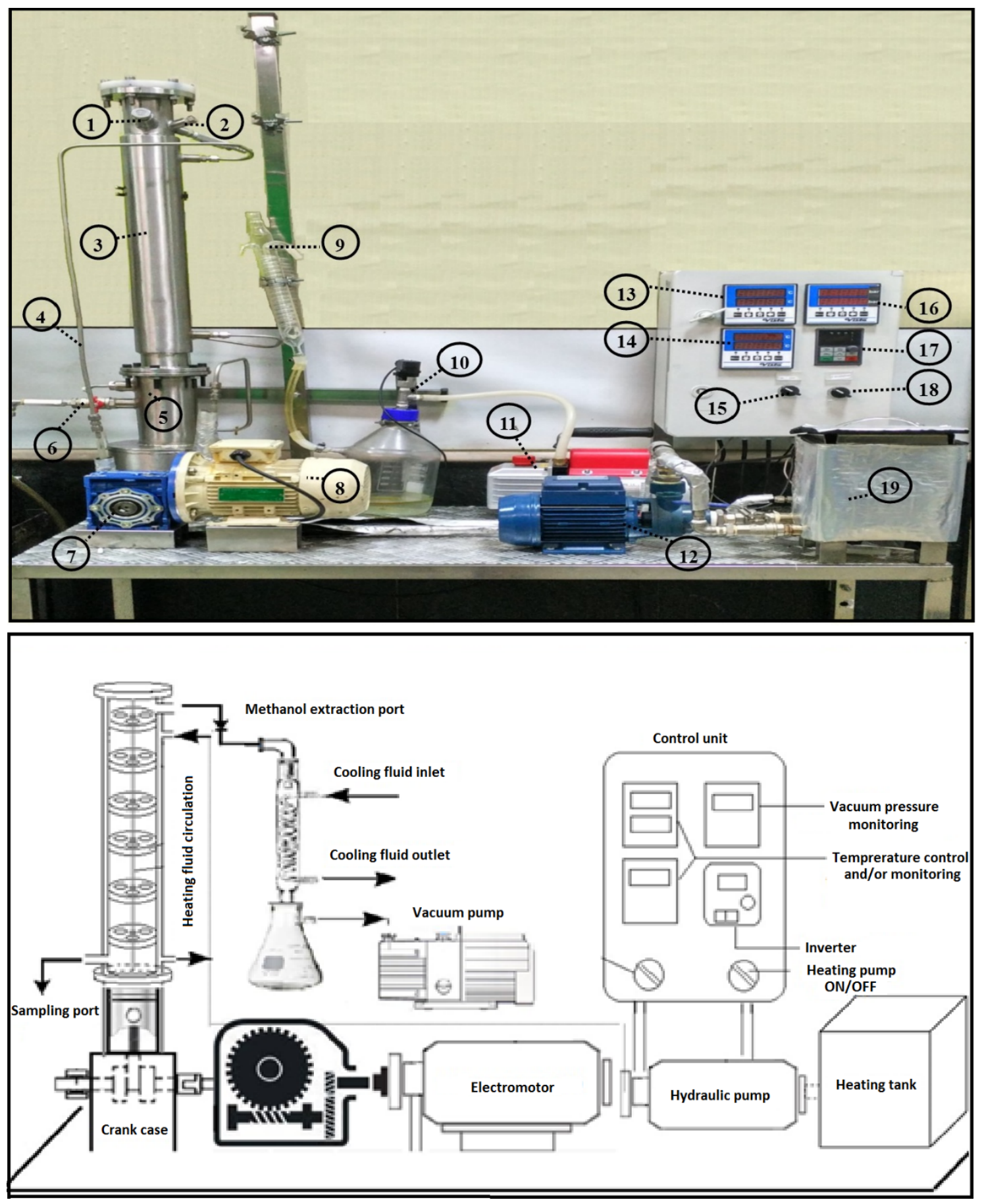

Figure 2: Different parts of VPC setup for biolubricant production (description of the parts are presented in Table 1); upper image: real setup, below image: schematic setup. 
Table 1: Technical specifications of the VPC setup shown in Figure 2.

\begin{tabular}{|c|c|c|c|}
\hline Number & Item & Number & Item \\
\hline 1 & Reactor input & 11 & $\begin{array}{l}\text { Vacuum pump (0.185 kW; } \\
220 \mathrm{~V})\end{array}$ \\
\hline 2 & Methanol extraction port & 12 & $\begin{array}{l}\text { Hydraulic pump (Veronella; } \\
0.37 \mathrm{~kW} ; 35.5 \mathrm{l} / \mathrm{min} \text { ) }\end{array}$ \\
\hline 3 & $\begin{array}{l}\text { Jacketed column }(\text { diameter }= \\
60 \mathrm{~mm} \text {; height: } 550 \mathrm{~mm})\end{array}$ & 13 & $\begin{array}{l}\text { Heating tank temperature } \\
\text { monitor and }\end{array}$ \\
\hline 4 & Heating fluid tube (steel) & 14 & The VPC temperature monitor \\
\hline 5 & $\begin{array}{l}\text { Jacketed cylinder with the } \\
\text { reciprocating piston inside }\end{array}$ & 15 & ON/OFF button \\
\hline 6 & Sampling port & 16 & Vacuum pressure monitor \\
\hline 7 & Gearbox (gear ratio of $1: 7.5$ ) & 17 & Inverter (Single phase, $50 \mathrm{~Hz}$ ) \\
\hline 8 & $\begin{array}{l}\text { Electromotor (HITECH- } \\
0.37 \mathrm{~kW} ; 2740 \mathrm{rpm})\end{array}$ & 18 & $\begin{array}{l}\text { ON/OFF button for } \\
\text { Circulation }\end{array}$ \\
\hline 9 & Condenser & 19 & $\begin{array}{l}\text { Heating tank (thermocouple } \\
\text { type } \mathrm{k}, 1 \mathrm{~kW} \text { ) }\end{array}$ \\
\hline 10 & $\begin{array}{l}\text { Methanol pot and the pressure } \\
\text { sensor ( } 0 \text { to }-1 \text { bar) }\end{array}$ & & \\
\hline
\end{tabular}

The VPC experimental rig consists of the jacketed column, the oscillation generating mechanism, a heating and circulation unit and a control unit (Fig. 2). Table 1 presents the technical specifications of different parts of the VPC setup.

The oscillation generating mechanism is comprised of a $0.37 \mathrm{~kW}$ electromotor, gearbox and a reciprocating piston in the cylinder. The heat and circulation unit consists of a tank equipped with a thermocouple (type $\mathrm{k} ; 1 \mathrm{~kW}$ ) and a hot oil pump to circulate the heating fluid in the outer jacket of the VPC. The control unit allows regulation of the oscillation frequency using the inverter. The inverter regulates the oscillation frequency by varying the $\mathrm{AC}$ current and subsequently regulates the electromotor speed, which in turn changes the oscillation frequency.

The temperature is measured via two PT-100 sensors (one is situated inside the VPC and the other in the heating tank). In addition, a power analyzer was serially connected 
to the power input circuit to measure the electrical power consumption of the device in each experimental run.

\subsection{Experimental procedure}

\subsubsection{FAME synthesis}

Fatty acid methyl ester (FAME) was produced by a $\mathrm{KOH}$-catalyzed transesterification reaction from WCO. For this purpose, the pre-treated $\mathrm{WCO}$ was sent to the reactor and was heated to $60^{\circ} \mathrm{C}$. The methanol to WCO molar ratio was $6: 1$ and the methoxide mixture was prepared by adding $1 \mathrm{wt} . \%$ (per oil weight) of $\mathrm{KOH}$ to methanol. The reaction was initiated after adding methoxide to $\mathrm{WCO}$ in the OBR and performed for 5 minutes. Other operating parameters (oscillation frequency $=4.1 \mathrm{~Hz}$; baffle spacing $=7$ $\mathrm{cm}$ and reaction temperature $=60^{\circ} \mathrm{C}$ ) were set to the optimal values obtained in our previous study for FAME production [37]. The reaction product was washed five times with hot water $\left(60^{\circ} \mathrm{C}\right)$ to remove residual glycerol and soap. The remaining methanol and water were then evaporated in an oven at $110^{\circ} \mathrm{C}$.

\subsubsection{TFATE synthesis}

The transesterification of TMP with FAME using potassium carbonate as a nonexpensive heterogeneous catalyst to form TFATE was carried out under different operating conditions based on the experimental design matrix proposed by RSM as detailed in section 2.5. Before starting each experiment, the reactor temperature brought to $110^{\circ} \mathrm{C}$ by heating the fluid inside the reactor jacket. This provided uniform heat transfer to the reagents inside the reactor. The methyl ester and TMP mixture was then poured inside the reactor, the catalyst was added and the vacuum pump was turned on, providing a constant vacuum of -0.3 bar to extract the methanol vapor and push the reaction in the forward direction. Fluid oscillation was then induced in vertical direction 
using the oscillation generating unit and the reciprocating piston at the bottom of the VPC. The extracted methanol was continuously condensed inside a collecting vessel. The reaction time for each experimental was 30 minutes and at the end of each run, the vacuum pump was stopped and $15 \mathrm{~mL}$ samples were taken from the VPC and quickly were quenched using icy water.

\subsection{Product analysis}

Proton nuclear magnetic resonance $\left({ }^{1} \mathrm{H}-\mathrm{NMR}\right)$ spectroscopy is a versatile tool which is used for the quantitative analysis and structural confirmation based on respective chemical shifts and the integral values of proton peaks. The products were characterized by ${ }^{1} \mathrm{H}-\mathrm{NMR}$ based on their proton chemical shifts of the reference model compounds and also with the help of literature reports $[38,39]$. In this study, the NMR spectrometer (400 MHz, Bruker, Germany) was used to record spectra for TFATE reaction yield analysis. The amount of $5 \mathrm{ml}$ of the crude product samples were pipetted into NMR tubes and then deuterated chloroform $\left(\mathrm{CDCl}_{3}\right.$; Sigma Aldrich) was added to dissolve the low polarity esterified reaction compounds. In the TFATE synthesis reaction, the methanol methylene proton resonance disappears as methyl esters are replaced with TMP esters. The characteristic resonance signal of TFATE and the reaction intermediate TFADE, are produced at 4.00 ppm and 4.02 ppm respectively, as shown in Fig. 3. Disappearance of the latter peak indicates that transesterification has neared completion. The yield of the transesterification reaction was calculated via computing the area under the peaks of 4 ppm and 4.02 ppm by Eq. 1 [38]:

$$
\text { Yield }=(1.02 \mathrm{~B}+\mathrm{A}) /(1.52 \mathrm{~B}+\mathrm{A})
$$


Where, $A$ and $B$ represent the area under the peaks with the resonance signal of 4.02 ppm and 4.00 ppm respectively. Manual baseline correction and integration was applied using the MestReNova v.11.04 software.

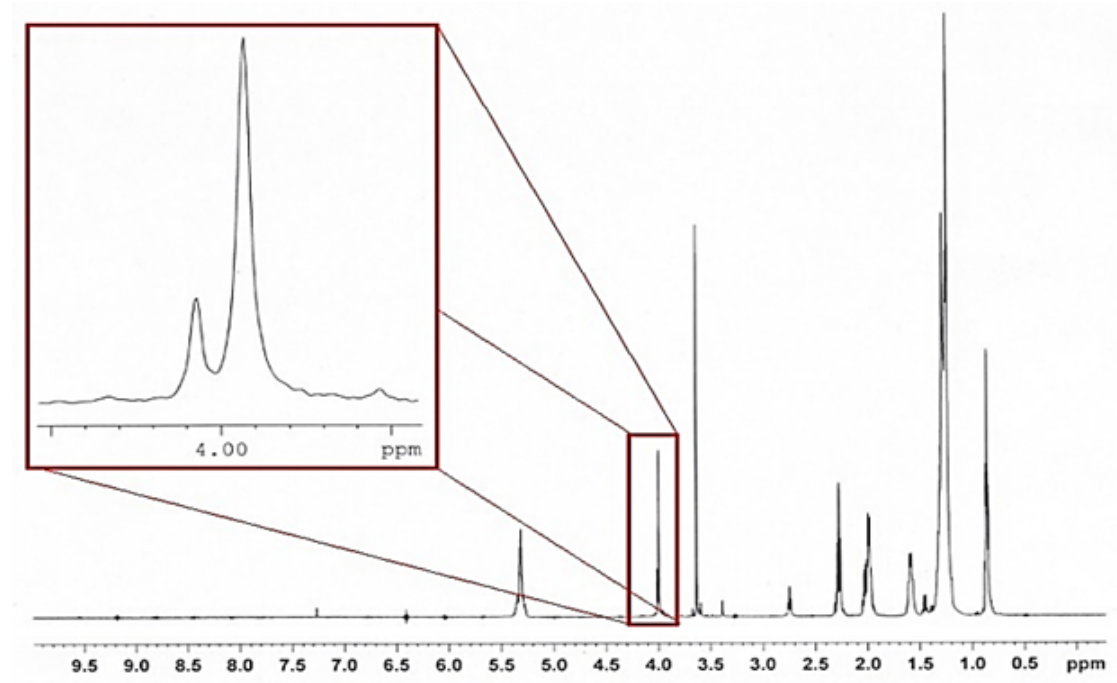

Figure 3: H-NMR spectrum of the biolubricant representing the content of TMP TE and DE, respectively.

\subsection{Experimental design}

Response Surface methodology (RSM) was applied to model and optimize the effects of independent operating parameters on experimental responses, i.e. TFATE reaction yield and the energy consumption. RSM is a collection of mathematical and statistical modeling techniques used for multiple regression analysis and to quantify the relationships between one or more measured responses and the vital input factors. There are typically two main purposes of considering a RSM model. Firstly, it can be employed to establish a relationship between independent operating parameters and a measured response that can then be used to predict the response for alternate values of the operating variables. Secondly, RSM can be used to determine the significance and 
the optimum settings of operating parameters that result in an optimum response over a predefined range of operating conditions. Another important advantage of using RSM is the fact that it decreases the number of required experiments for performance assessment in industrial applications [40]. In this study, a 3-levels-4-factors Central Composite Design (CCD) was used to evaluate the interactions of operating parameters, namely oscillation frequency, baffle spacing, FAME to TMP molar ratio and catalyst loading in the VPC and their effects on the experiment responses. The CCD design, including 24 factorial points was applied for fitting a second-order response surface. The advantage of using CCD to Box-Behnken design (BBD) is that in the CCD model there are two extra experimental levels over both the initial and final levels for each experimental factor to increase the accuracy of the regression modeling. The experimental runs were randomized to minimize the effects of unexpected errors in the observed responses. Table 2 shows the encoded and physical levels of the independent variables used for the CCD design and Table 3 tabulates the experimental runs performed. Using Design-Expert ${ }^{\circledR}$ Software (version 7), the least squares method was then used to suggest the best equation type to relate the experimental reaction yield and VPC power consumption to the operating variables.

Table 2: The RSM-CCD experimental matrix.

\begin{tabular}{|c|c|c|c|c|c|c|c|c|}
\hline & \multirow{2}{*}{ Variables } & \multirow{2}{*}{ Unit } & \multirow{2}{*}{ Symbols } & \multicolumn{5}{|c|}{ Levels of each factor (encoded values) } \\
\hline & & & & $-\alpha$ & -1 & 0 & 1 & $+\alpha$ \\
\hline \multirow{3}{*}{$\begin{array}{r}\text { Operating } \\
\text { parameters }\end{array}$} & Oscillation frequency & $\mathrm{Hz}$ & $X_{1}$ & 0.9 & 1.8 & 2.7 & 3.6 & 4.5 \\
\hline & Baffle spacing & $\mathrm{cm}$ & $X_{2}$ & 2.5 & 5 & 7.5 & 10 & 12.5 \\
\hline & $\begin{array}{l}\text { FAME:TMP molar } \\
\text { ratio }\end{array}$ & - & $X_{3}$ & 3 & 4 & 5 & 6 & 7 \\
\hline
\end{tabular}


$\begin{array}{llllllll}\text { Catalyst loading } & \% & X_{4} & 0.25 & 1 & 1.75 & 2.5 & 3.25\end{array}$

\begin{tabular}{|c|c|c|c|c|c|c|c|c|}
\hline \multirow{2}{*}{ Responses } & Reaction yield & $\%$ & $Y_{l}$ & - & - & - & - & - \\
\hline & Power & $\mathrm{kW} / \mathrm{m}^{3}$ & $Y_{2}$ & - & - & - & - & - \\
\hline
\end{tabular}

Table 3: The central composite design of experiments proposed by RSM.

\begin{tabular}{|c|c|c|c|c|}
\hline Run & $\begin{array}{c}X_{I} \\
\text { Frequency } \\
(\mathrm{Hz})\end{array}$ & $\begin{array}{c}X_{2} \\
\text { Baffle spacing } \\
(\mathrm{m})\end{array}$ & \begin{tabular}{l}
\multicolumn{1}{c}{$X_{3}$} \\
FAME:TMP \\
molar ratio
\end{tabular} & $\begin{array}{c}X_{4} \\
\text { Catalyst } \\
\text { loading (\%) }\end{array}$ \\
\hline 1 & 3.6 & 0.05 & 6 & 2.5 \\
\hline 2 & 3.6 & 0.10 & 4 & 2.5 \\
\hline 3 & 2.7 & 0.075 & 5 & 1.75 \\
\hline 4 & 1.8 & 0.10 & 6 & 1 \\
\hline 5 & 4.5 & 0.075 & 5 & 1.75 \\
\hline 6 & 2.7 & 0.075 & 5 & 0.25 \\
\hline 7 & 0.9 & 0.075 & 5 & 1.75 \\
\hline 8 & 1.8 & 0.10 & 4 & 1 \\
\hline 9 & 2.7 & 0.025 & 5 & 1.75 \\
\hline 10 & 1.8 & 0.10 & 6 & 2.5 \\
\hline 11 & 3.6 & 0.05 & 6 & 1 \\
\hline 12 & 1.8 & 0.05 & 4 & 1 \\
\hline 13 & 2.7 & 0.075 & 5 & 1.75 \\
\hline 14 & 2.7 & 0.125 & 5 & 1.75 \\
\hline 15 & 3.6 & 0.10 & 4 & 1 \\
\hline 16 & 1.8 & 0.05 & 6 & 1 \\
\hline 17 & 2.7 & 0.075 & 5 & 1.75 \\
\hline 18 & 3.6 & 0.05 & 4 & 1 \\
\hline 19 & 2.7 & 0.075 & 3 & 1.75 \\
\hline 20 & 3.6 & 0.05 & 4 & 2.5 \\
\hline 21 & 1.8 & 0.05 & 6 & 2.5 \\
\hline 22 & 2.7 & 0.075 & 5 & 3.25 \\
\hline 23 & 2.7 & 0.075 & 5 & 1.75 \\
\hline 24 & 3.6 & 0.10 & 6 & 1 \\
\hline 25 & 1.8 & 0.10 & 4 & 2.5 \\
\hline 26 & 2.7 & 0.075 & 5 & 1.75 \\
\hline 27 & 2.7 & 0.075 & 7 & 1.75 \\
\hline
\end{tabular}




\begin{tabular}{lllll}
\hline 28 & 2.7 & 0.075 & 5 & 1.75 \\
29 & 1.8 & 0.05 & 4 & 2.5 \\
30 & 3.6 & 0.10 & 6 & 2.5 \\
\hline
\end{tabular}

\section{Results and discussions}

\subsection{RSM model and statistical analysis}

Based on the results of the analysis of variance (ANOVA), the quadratic and the linear polynomial equations were proposed by Design Expert software as the most suitable mathematical models for estimation of TFATE reaction yield $\left(Y_{l}\right)$ and the power consumption $\left(Y_{2}\right)$, respectively (Table 4 and Table 5). The general form of the linear and quadratic polynomial equations are as follows (Eq. 2 and Eq. 3):

Table 4: Analysis of variance of the quadratic model used for estimation of reaction yield.

\begin{tabular}{ccccccc}
\hline Source & $\begin{array}{c}\text { Sum of } \\
\text { Squares }\end{array}$ & df & $\begin{array}{c}\text { Mean- } \\
\text { square }\end{array}$ & F-value & p-value & \\
\hline Model & 211.73 & 14 & 15.12 & 7.23 & 0.0007 & Significant \\
$X_{1}$-Frequency & 38.88 & 1 & 38.88 & 18.58 & 0.0010 & \\
$X_{2}$-Baffle & 7.53 & 1 & 7.53 & 3.60 & 0.0821 & \\
spacing & & & & & & \\
$X_{3}$-Molar ratio & 11.88 & 1 & 11.88 & 5.68 & 0.0345 & \\
$X_{4}$-Catalyst & 3.99 & 1 & 3.99 & 1.91 & 0.1926 & \\
loading & & & & & & \\
$X_{1 .} X_{2}$ & 0.098 & 1 & 0.098 & 0.047 & 0.8324 & \\
$X_{1} . X_{3}$ & 0.60 & 1 & 0.60 & 0.29 & 0.6031 & \\
$X_{1 .} X_{4}$ & 7.37 & 1 & 7.37 & 3.52 & 0.0851 & \\
$X_{2} \cdot X_{3}$ & 3.19 & 1 & 3.19 & 1.53 & 0.2403 & \\
$X_{2} . X_{4}$ & 10.64 & 1 & 10.64 & 5.08 & 0.0436 & \\
$X_{3} . X_{4}$ & 57.83 & 1 & 57.83 & 27.64 & 0.0002 & \\
$X_{1}{ }^{2}$ & 26.43 & 1 & 26.43 & 12.63 & 0.0040 &
\end{tabular}




$\begin{array}{ccccccc}X_{2}^{2} & 16.95 & 1 & 16.95 & 8.10 & 0.0147 & \\ X_{3}{ }^{2} & 11.14 & 1 & 11.14 & 5.32 & 0.0397 & \\ X_{4}{ }^{2} & 8.67 & 1 & 8.67 & 4.14 & 0.0645 & \\ \text { Residual } & 25.11 & 12 & 2.09 & & & \\ \text { Lack of fit } & 20.00 & 7 & 2.86 & 2.80 & 0.1374 & \begin{array}{c}\text { not } \\ \text { significant }\end{array} \\ \text { Pure error } & 5.10 & 5 & 1.02 & & & \\ \text { Cor Total } & 236.83 & 26 & & & & \\ \text { R-Squared } & 0.8575 & & & & & \\ \text { Std. Dev. } & 1.45 & & & & & \\ \text { C.V. \% } & 1.88 & & & & & \end{array}$

Table 5: Analysis of variance of the quadratic model for estimation of the power consumption.

\begin{tabular}{ccccccc}
\hline Source & $\begin{array}{c}\text { Sum of } \\
\text { Squares }\end{array}$ & df & $\begin{array}{c}\text { Mean- } \\
\text { square }\end{array}$ & F-value & p-value & \\
\hline Model & 248,300 & 4 & $62,071.55$ & 452.46 & $<$ & Significant \\
& & & & & 0.0001 & \\
$X_{1}$-Frequency & 240,100 & 1 & 240,100 & $1,750.10$ & $<$ & \\
X2-Baffle & $8,180.67$ & 1 & $8,180.67$ & 59.63 & $<$ & \\
spacing & & & & & 0.0001 & \\
$X_{3}$-Molar ratio & 3.89 & 1 & 3.89 & 0.028 & 0.8676 & \\
$X_{4}$-Catalyst & 9.61 & 1 & 9.61 & 0.070 & 0.7935 & \\
loading & & & & & & not \\
Residual & $3,429.69$ & 25 & 137.19 & & & \\
Lack of fit & $2,721.82$ & 20 & 136.09 & 0.96 & 0.5785 & \\
Pure error & 707.86 & 5 & 141.57 & & & \\
Cor Total & 251,700 & 29 & & & & \\
Std. Dev. & 248,300 & & & & & \\
C.V. \% & 240,100 & & & & & \\
\hline
\end{tabular}




$$
\begin{aligned}
& Y=\lambda_{0}+\sum_{i=1}^{K} \lambda_{i} X_{i}+\varepsilon \\
& Y=\lambda_{0}+\sum_{i=1}^{K} \lambda_{i} X_{i}+\sum_{i=1}^{K} \lambda_{i i} X_{i}^{2}+\sum_{i=1}^{K} \sum_{j=i+1}^{K} \lambda_{i j} X_{i} X_{j}+\varepsilon
\end{aligned}
$$

where, $Y$ is the response, $i$ and $j$ are the linear and quadratic coefficients, respectively, $k$ is the number of studied and optimized factors in the experiments, $\lambda$ is the regression coefficient, $\varepsilon$ is the modeling error and $X_{i}$ and $X_{j}$ are the independent variables. The quadratic regression model for the estimation of the TFATE reaction yield and the power consumption of the experimental rig based on the coded values of operating parameters were obtained from Eq. 4 and Eq. 5 respectively.

$$
\begin{aligned}
& Y_{1}=+76.40+1.34 X_{1}-0.59 X_{2}-0.93 X_{3}+0.52 X_{4}+0.085 X_{1} X_{2}-0.21 X_{1} X_{3}-0.73 X_{1} X_{4} \\
& +0.48 X_{2} X_{3}-0.88 X_{2} X_{4}+2.06 X_{3} X_{4}+1.01 X_{1}^{2}-0.81 X_{2}^{2}+0.90 X_{3}^{2}-0.76 X_{4}^{2} \\
& Y_{2}=+139.27+13.34 X_{1}-7.38 X_{2}+0.40 X_{3}-0.84 X_{4}
\end{aligned}
$$

where $Y_{1}$ and $Y_{2}$ are the TFATE reaction yield and the power consumption (responses), $X_{1}$ is the oscillation frequency, $X_{2}$ is the baffle spacing, $X_{3}$ is the FAME to TMP molar ratio and $X_{4}$ is the catalyst loading.

As it can be seen in Table 4, the suggested model is statistically significant on the confidence level of $99 \%$ with a p-value of 0.0007 (less than 0.01 ). According to the resulting values of sum of squares and the p-values, it can be concluded that both the TFATE reaction yield and the power consumption are mostly dependent on the oscillation frequency. In addition, it can be understood that the FAME to TMP molar ratio and the interaction between the molar ratio and catalyst loading have significant statistical effects on TFATE reaction yield compared with the other operating parameters. It is interesting to see that although the effect of baffle spacing on reaction 
yield is not statistically significant, the effects of its squared value $\left(X_{2}^{2}\right)$ and the interaction of baffle spacing and catalyst loading $\left(X_{2} \cdot X_{4}\right)$ are not negligible. The statistical significance of $X_{2}^{2}$ means that the variation in reaction yield by changing the levels of baffle spacing is of second order (parabolic). According to the results in Table 5, it can be understood that the baffle spacing has a significant effect on the power consumption, though it has less sum of squares and F-value and thereby has less influence than the oscillation frequency.

\subsection{Effect of operating parameters on TFATE reaction yield}

The effect of experimental operating parameters on reaction yield are shown as threedimensional response surfaces and contour plots in Fig. 4. In each figure, the other operating parameters are set at their zero-coded level (as mentioned in Table 2).

\subsubsection{Oscillation frequency}

The effect of the interaction of oscillation frequency and baffle spacing on reaction yield is shown in Fig. 4(a). This figure reveals that the highest TFATE reaction yield is obtained at the highest oscillation frequency, whilst baffle spacing has little effect. In fact, increasing the oscillation frequency intensifies the mixing process due to the interaction of the flow with the multi-orifice baffles. This causes the formation of vortices, as well as a decrease in reactants drop size and therefore an increase in interfacial area between the reactants. As a result, mass transfer and consequently reaction yield increase. These observations are similar to those made by [31] who also found that the reaction yield increased with increasing oscillation frequency at a reaction temperature of $130^{\circ} \mathrm{C}$. However, they also showed that excessive values of oscillation frequency caused a reduction in the reaction yield. The cause of this reduction was explained by the evaporation of methyl ester due to the friction being 
developed between the surfaces of pistons and the inner column of VPC at higher oscillatory speeds. This decrease in yield was not observed in the present study, however, perhaps since the reaction temperature was to $110^{\circ} \mathrm{C}$, which is significantly lower than the methyl ester evaporation temperature $\left(150{ }^{\circ} \mathrm{C}\right)$.

Fig. 4(b) shows the effect of the interaction between oscillation frequency and the FAME to TMP molar ratio on TFATE reaction yield. The 3D surface clearly reveals that the maximum reaction yield is obtained at highest level of oscillation frequency and lowest level of molar ratio and the minimum reaction yield is obtained at the oscillation frequency of nearly $2 \mathrm{~Hz}$ and a molar ratio of 5.5.

(a)
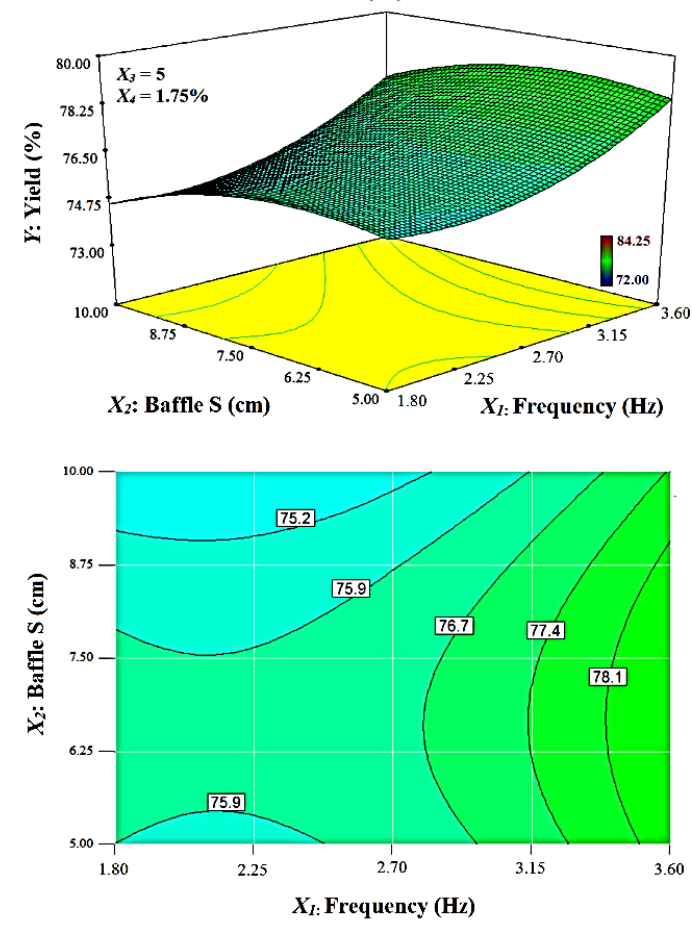

(b)
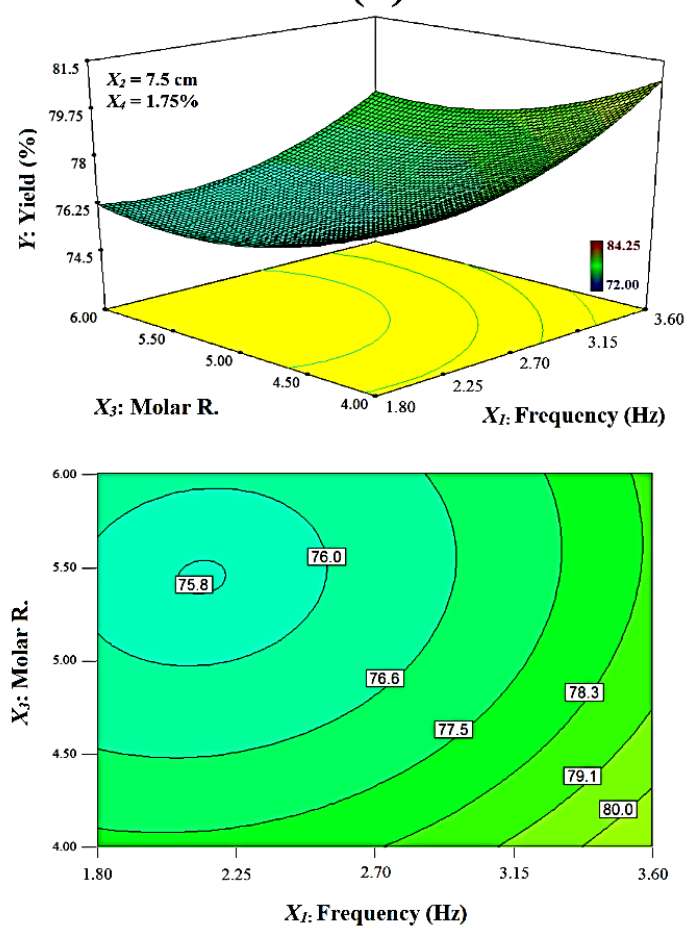
(c)
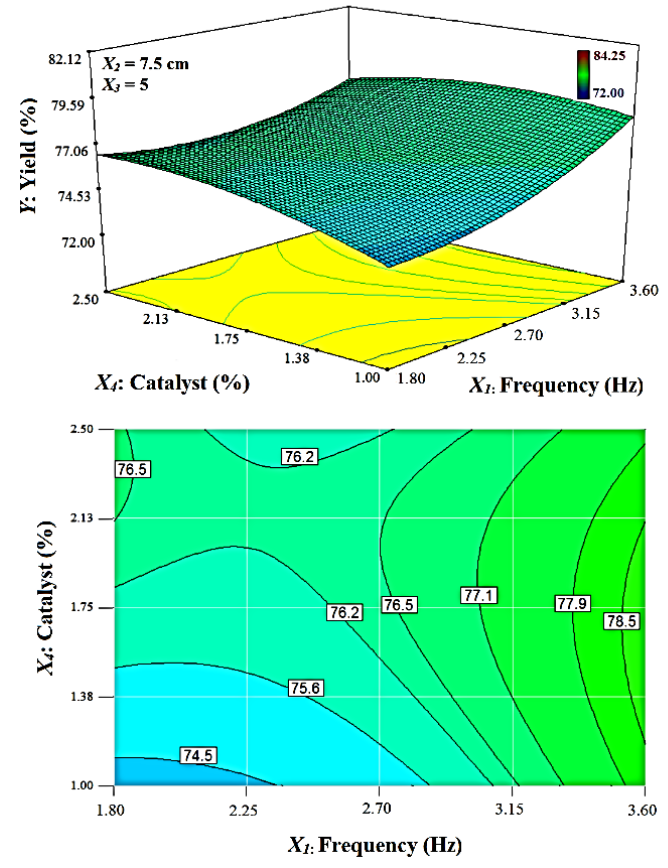

(e)
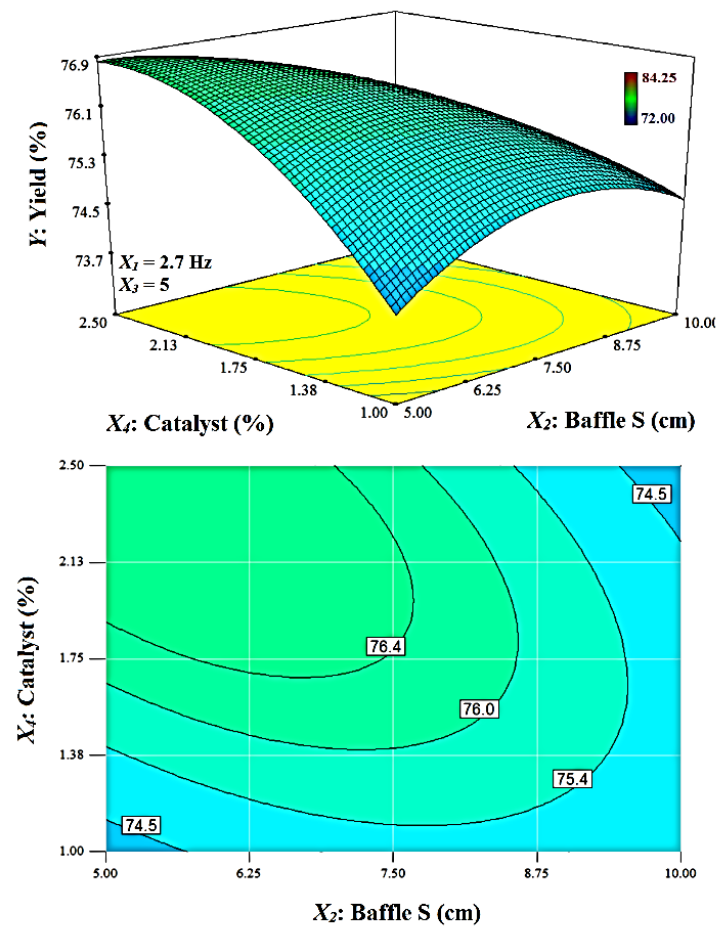

(d)
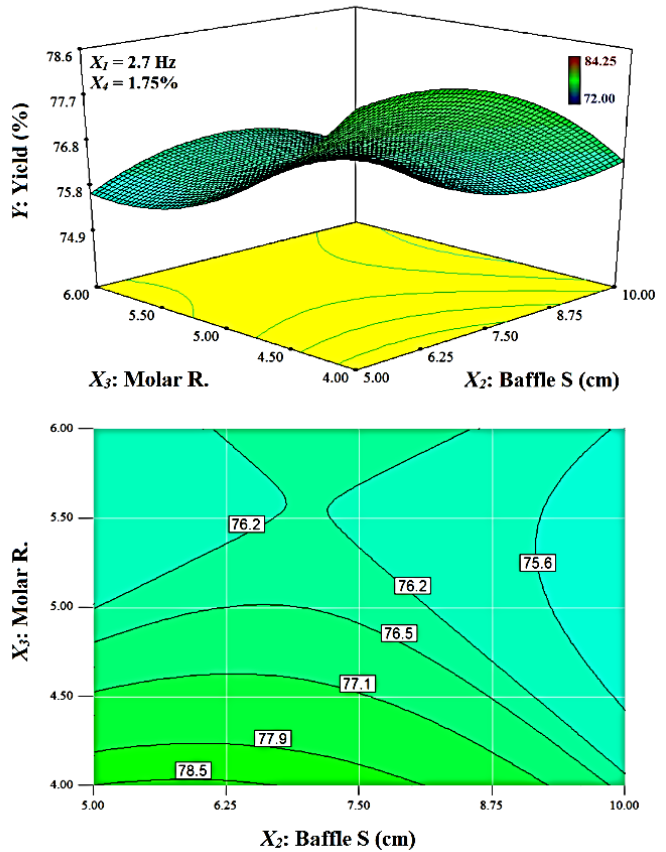

(f)
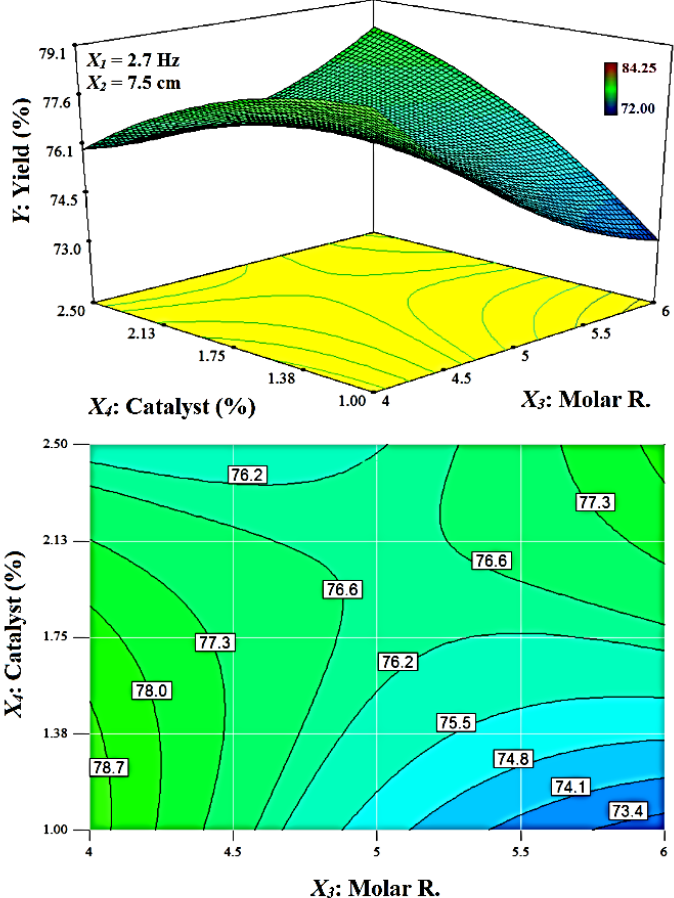

Figure 4: Effect of interaction between oscillation frequency and baffle spacing on reaction yield; (reaction time $=30 \mathrm{~min})$. Top image: surface response; bottom image: contour plot. 
According to contour lines in Fig. 4(b), it is possible that for lower oscillation frequencies (less than $3 \mathrm{~Hz}$ ), where mixing is not so vigorous, it is the lower molar ratios that push the transesterification reaction forward. The interaction between oscillation frequency and catalyst loading is presented in Fig. 4(c). According to the contour lines in Fig. 4(c), it can be understood that at lower oscillation frequencies, the reaction yield increases by $2 \%$ when the catalyst loading increases from $1 \%$ to $2.5 \%$. However, with oscillation frequencies greater than $2.7 \mathrm{~Hz}$, the oscillation frequency is the only dominant factor affecting the reaction yield. Indeed, the yield is enhanced by increasing the oscillation frequency for all catalyst loading levels, but at higher catalyst concentrations, this increase is less due to a higher saponification rate. These results were similar to the results obtained by $[41,42]$.

\subsubsection{Baffle spacing}

The baffle spacing in the VPC can influence the formation of vortices and hence mixing performance. Indeed, short inter-baffle distances prevent sufficient growth of vortices, whilst excessive baffle spacing will cause stagnant regions, which decreases the mixing quality [33]. According to Fig. 4(d), the reaction yield only slightly decreases when the baffle spacing increases. Although the effect of baffle spacing $\left(X_{2}\right)$ on the reaction yield is still not significant, the quadratic values of baffle spacing $\left(X_{2}^{2}\right)$ shown in Table 4 are statistically significant at the 95\% level. This result is slightly different from what we obtained for methyl ester reaction yield, where the effect of baffle spacing on yield was found to be insignificant [37]. This could be due to the fact that the biolubricant has a significantly higher viscosity than methyl ester (approximately three times greater at 40) and therefore the vortices created by the 
interaction of the baffles and the pulsed flow would be typically smaller and more easily affected by the baffle spacing.

The effect of interaction of baffle spacing and catalyst loading $\left(X_{2} . X_{4}\right)$ on reaction yield is represented in Fig. 4(e). It is interesting to note that in lower catalyst levels, the yield is nearly constant at all baffle spacing levels; however, as the catalyst concentration increases from $1 \%$ to $2.5 \%$, the baffle spacing has a more effective role such that the highest yield is obtained at baffle spacing of $5 \mathrm{~cm}\left(1.45 d_{e}\right)$ and a catalyst concentration of $2.5 \%$. This can be attributed to the fact that with lower baffle spacing, there is more interaction between solid catalyst particles and the reactants due to improved mixing and recirculation, which causes higher mass transfer, thereby increasing the reaction yield.

\subsubsection{FAME to TMP Molar ratio}

According to Fig. 4(b), Fig. 4(d) and Fig. 4(f), the highest TFATE reaction yields are obtained with the lowest FAME to TMP molar ratio of $4: 1$. In a recent research study by Hamidah et al. [31], the effect of FAME to TMP molar ratio (ranging from 3.5:1 to 4.3:1) on palm oil based TFATE was investigated. Their results showed that the FAME to TMP molar ratio had influence on TFATE reaction yield over the chosen range. However, they reported that highest reaction yields were obtained with a molar ratio of 3.9:1, which is almost equal to the optimal value obtained in the present study. In fact, the value of the molar ratio should be higher than the TFATE reaction stoichiometric ratio (3:1), however excessive values of the molar ratio will promote the reverse reaction, causing a reduction in the final transesterification reaction yield and making the purification process more difficult and expensive [43]. 


\subsubsection{Catalyst loading}

According to Table 4, the interaction between the molar ratio and catalyst loading $\left(X_{3} . X_{4}\right)$ has the highest $\mathrm{F}$-value of the different interactions, thereby showing that it has a considerable influence on reaction yield. It is interesting to see that in lower molar ratio levels (4:1 to $4.5: 1)$, an increase in catalyst concentration may cause a slight decrease in reaction yield, whilst at molar ratio levels of $4.5: 1$ to $5: 1$, the yield is hardly effected by catalyst loading levels and then at higher molar ratios, the reaction yield increases from $73.4 \%$ to $78 \%$ while the catalyst loading increases from $1 \%$ to $2.5 \%$. At lower molar ratios, adding excess catalyst amounts will exacerbate the saponification reaction rate and thereby will cause reduction on TFATE yield [43]. However, at higher molar ratios, due to increased FAME content, the interaction between TMP and catalyst decreases and therefore higher catalyst concentration will be advantageous in promoting reaction performance and consequently the reaction yield.

\subsection{Effect of operating parameters on the power consumption}

The effect of each operating parameters on the power consumption is illustrated in Fig. 5. It is obvious that oscillation frequency is the dominant factor influencing on power consumption of the VPC rig. According to the surface plot in Fig. 5, the power consumption increases linearly with the increase in oscillation frequency as there is nearly $500 \mathrm{~kW}$ rise in power consumption when the oscillation frequency increases from $1.8 \mathrm{~Hz}$ to $3.6 \mathrm{~Hz}$. In addition, there is a slight decrease in power consumption at higher baffle spacing levels due to lower resistant energy caused by the baffles that block the fluid's fluctuating motion. 

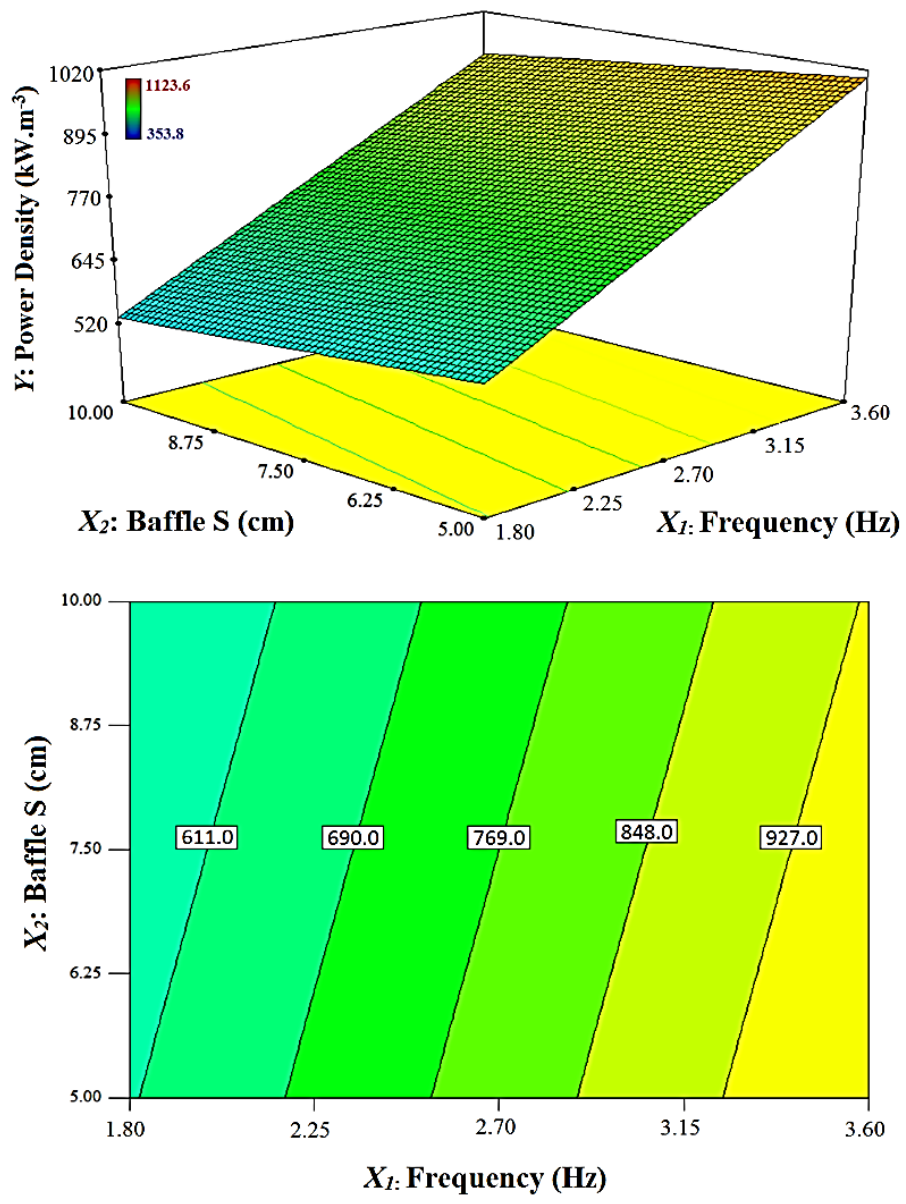

Figure 5: Effects of oscillation frequency and baffle spacing on power consumption of the VPC setup.

\subsection{Process optimization}

The optimum values of the various operating parameters were calculated using Design Expert® Software (version 7) such that the highest TFATE reaction yield $\left(Y_{l}\right)$ and the lowest power consumption $\left(Y_{2}\right)$ were obtained. It is obvious that the lower reaction yield will cause a reduction in the quality of final product and leads to a globally higher energy consumption since additional separation and purification processes would be required. Therefore, the weights for $Y_{1}$ and $Y_{2}$ were selected as 5 of 5 and 1 of 5 respectively. Table 6 shows the top-10 optimal sets of operating parameters that allow maximum TFATE reaction yield and minimum power consumption to be achieved. 
As it can be seen in Table 6, based on the selected criteria in finding the best solution, the highest value of desirability is obtained with the highest oscillation frequency (3.6 $\mathrm{Hz}$ ) and almost the lowest baffle spacing $(5 \mathrm{~cm})$. The other suggested alternatives are also very close to these values; however, the last solution shows a set of different values. In this solution, a decrease in the oscillation frequency and an increase in the inter-baffle space leads to an almost two-fold decrease in power consumption (from $1,006.0 \mathrm{~kW} / \mathrm{m}^{3}$ to $531.6 \mathrm{~kW} / \mathrm{m}^{3}$ ) however it results in more than 4 percent decrease in the final reaction yield, which is not negligible. Therefore, the first solution with the highest desirability was selected as the optimum solution.

Table 6. Top-10 optimal solutions suggested by RSM to obtain desired responses.

\begin{tabular}{|c|c|c|c|c|c|c|c|}
\hline \multirow[b]{2}{*}{ Solutions } & \multicolumn{4}{|c|}{ Operating parameters } & \multicolumn{2}{|c|}{ Responses } & \multirow[b]{2}{*}{ Desirability } \\
\hline & $\begin{array}{c}X_{I}: \\
\text { Frequency } \\
(\mathrm{Hz})\end{array}$ & $\begin{array}{c}X_{2}: \\
\text { Baffle } \\
\text { spacing } \\
(\mathrm{cm})\end{array}$ & $\begin{array}{c}X_{3}: \\
\text { Molar } \\
\text { ratio }\end{array}$ & $\begin{array}{c}X_{4}: \\
\text { Catalyst } \\
(\%)\end{array}$ & $\begin{array}{c}Y_{l}: \\
\text { Yield } \\
(\%)\end{array}$ & $\begin{array}{c}Y_{2}: \\
\text { Power } \\
\left(\mathrm{kW} \cdot \mathrm{m}^{-3}\right)\end{array}$ & \\
\hline 1 & 3.60 & 5.02 & 4.00 & 1.00 & 83.33 & $1,006.0$ & 0.685 \\
\hline 2 & 3.60 & 5.00 & 4.02 & 1.00 & 83.28 & $1,006.4$ & 0.683 \\
\hline 3 & 3.60 & 5.48 & 4.00 & 1.00 & 82.81 & 999.4 & 0.665 \\
\hline 4 & 3.60 & 5.56 & 4.00 & 1.00 & 82.70 & 998.0 & 0.661 \\
\hline 5 & 3.55 & 5.00 & 4.00 & 1.12 & 82.59 & 994.2 & 0.658 \\
\hline 6 & 3.60 & 5.86 & 4.00 & 1.00 & 82.40 & 993.8 & 0.649 \\
\hline 7 & 3.60 & 5.00 & 4.36 & 1.00 & 82.28 & $1,006.6$ & 0.631 \\
\hline 8 & 3.54 & 5.01 & 6.00 & 1.00 & 81.62 & 993.6 & 0.608 \\
\hline 9 & 3.56 & 5.04 & 6.00 & 1.00 & 81.64 & 997.4 & 0.606 \\
\hline 10 & 1.80 & 10.00 & 5.96 & 2.49 & 79.06 & 531.6 & 0.605 \\
\hline
\end{tabular}


Table 7: Physicochemical properties of WCO-based TFATE and ISO requirements.

\begin{tabular}{lcccc}
\hline \multicolumn{1}{c}{ Properties } & Test standard & TFATE & ISO VG10 & ISO VG22 \\
\hline Density, $15{ }^{\circ} \mathrm{C}\left(\mathrm{Kg} \cdot \mathrm{m}^{-3}\right)$ & ASTM D4052 & 0.895 & - & - \\
Viscosity, $40{ }^{\circ} \mathrm{C}(\mathrm{cSt})$ & ASTM D445 & 15.5 & $>9$ & $>19.8$ \\
Viscosity, $100{ }^{\circ} \mathrm{C}(\mathrm{cSt})$ & ASTM D445 & 4.24 & $>2.68$ & 4.3 \\
Viscosity index & ASTM D2270 & 196 & 104 & 107 \\
Flash point $\left({ }^{\circ} \mathrm{C}\right)$ & ASTM D93 & 198 & 154 & 203 \\
Pour point $\left({ }^{\circ} \mathrm{C}\right)$ & ASTM D97 & -9 & -6 & -6 \\
\hline
\end{tabular}

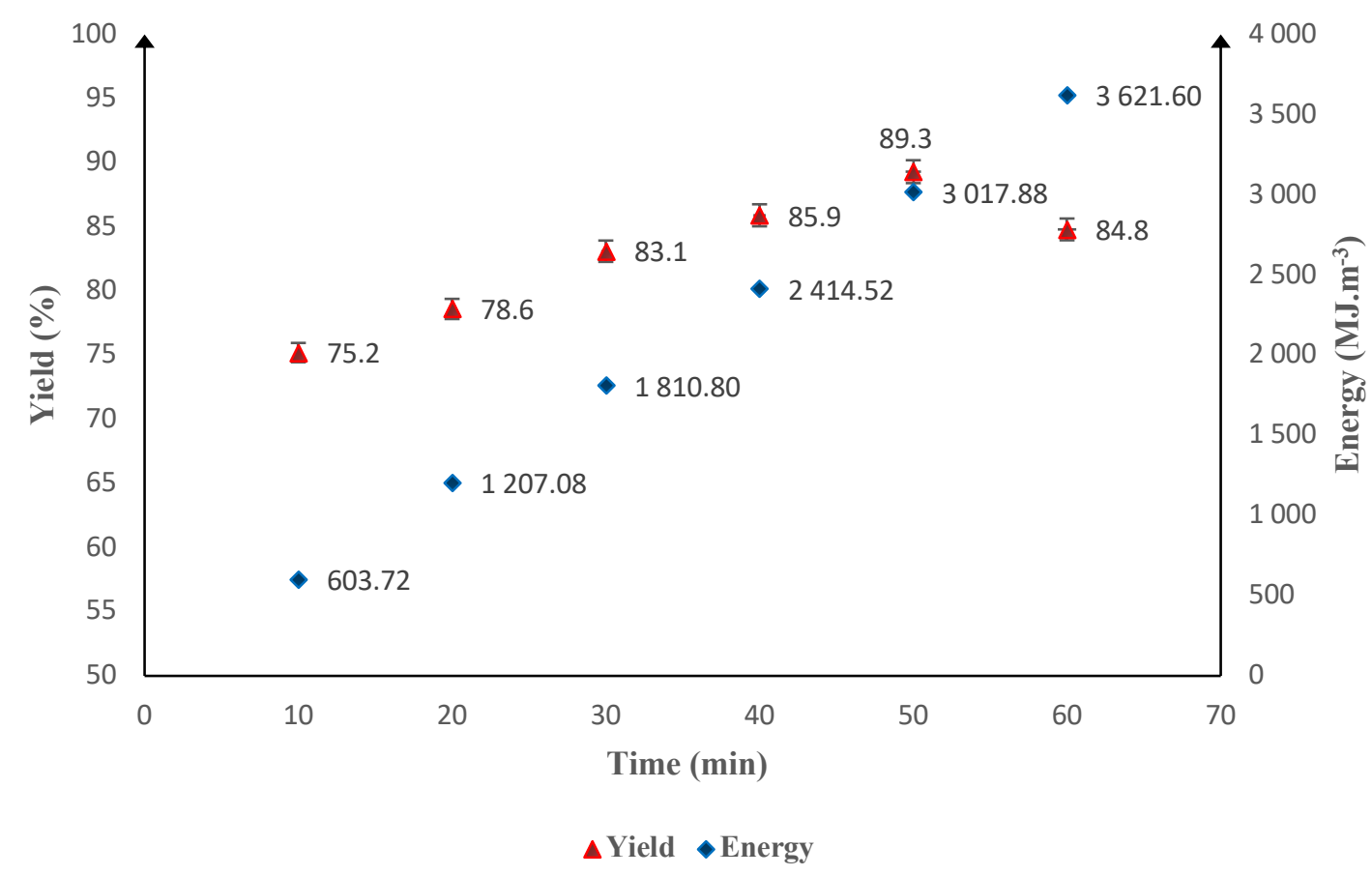

Figure 6: Effect of reaction time on TFATE yield and energy consumption.

Fig. 6 presents the reaction yield and power consumption as a function of reaction time. As it can be seen the reaction yield steadily increases from $75.2 \%$ to $89.3 \%$ between $10 \mathrm{~min}$ to $60 \mathrm{~min}$ while the energy consumption clearly has a linear increase from 603.7 to $3,621.6 \mathrm{MJ} . \mathrm{m}^{-3}$ due to its direct dependence on the reaction time. The 
highest yield was obtained as $89.3 \%$ at 50 min while the operating parameters were fixed at their optimum levels $\left(X_{I}=3.6 \mathrm{~Hz} ; X_{2}=5 \mathrm{~cm} ; X_{3}=4 ; X_{4}=1 \%\right)$. The yield slightly decreased $3.5 \%$ when the reaction time increased from $50 \mathrm{~min}$ to $60 \mathrm{~min}$, which can be explained by the reversible nature and the equilibrium position of the transesterification reaction.

\subsection{Analysis of physicochemical properties}

The physicochemical properties of the TFATE were measured in order to characterize its potential as a lubricant for industrial applications according to the ISO viscosity grade (VG) standard. The ISO VG is a standardized classification for all industrial lubricants based on their kinematic viscosity at $40{ }^{\circ} \mathrm{C}$. As shown in Table 7, the physicochemical properties of WCO-based TFATE, including viscosity, viscosity index (VI), flash point and pour point, meet the requirements of ISO VG10.

The results clearly show that the final TFATE product has superior performance in terms of VI, flash point and pour point, which are the principal lubricant properties, compared with the ISO VG10 standard. These advantages will lead to a more stable viscosity at higher temperatures, safer transport and storage and better lubricant performance at cold temperatures. In addition, these superior properties will decrease the consumption of lubricant additives and thereby further lower the price of the final product which clearly makes the WCO-based TFATE an attractive and sustainable alternative to petroleum-based lubricants.

\section{Conclusions}

The optimal operating parameters to achieve the highest TFATE reaction yield and the lowest VPC power consumption were obtained with an oscillation frequency of $3.6 \mathrm{~Hz}$, 
a baffle spacing of $5 \mathrm{~cm}\left(1.45 d_{e}\right)$, a molar ratio of $4: 1$ and a catalyst loading of $1 \%$ in 30 minutes of reaction time. Using these optimal values, the optimum TFATE reaction yield and VPC power consumption of $83.33 \%$ and $1,006 \mathrm{~kW} / \mathrm{m}^{3}$, respectively, where obtained. It was found that the oscillation frequency and the interaction of molar ratio and catalyst loading are the most influential factors (p-value of $X_{3} . X_{4}=0.0002$ ) in enhancing the yield of biolubricant in the VPC. In spite of the fact that the oscillation frequency has far more significant effects on the responses, the baffle spacing was found as an influential factor in terms of both reaction yield ( $p$-value of $X_{2}^{2}=0.0147$ ) and power consumption (p-value of $X_{2}<0.0001$ ). This is relatively different with what had been found in our previous research study about methyl ester production in the VPC where the baffle spacing was not a significant factor. However, the optimal baffle spacing found here is in agreement with the literature recommendations. Finally, the physicochemical analysis of TFATE showed an excellent compatibility with the ISO VG10 base oil standard. Moreover, TFATE lubricant made from WCO based biodiesel has significantly improved properties (VI, flash point and pour point) compared with the ISO VG10 base oil standard, which clearly makes it an attractive and sustainable alternative to petroleum-based lubricants.

\begin{tabular}{|ll|}
\hline \begin{tabular}{ll} 
Nomenclature & \\
$B$ & area under the peak with the resonance signal of $4.02 \mathrm{ppm}$ \\
$d$ & internal diameter \\
$d_{e}$ & effective internal diameter \\
$i$ & linear and quadratic coefficient \\
$j$ & linear and quadratic coefficient \\
\hline
\end{tabular} \\
\hline
\end{tabular}




\begin{tabular}{|c|c|}
\hline$k$ & number of optimized factors in the experiments \\
\hline$l$ & inter-baffle spacing \\
\hline$X_{1}$ & oscillation frequency \\
\hline$X_{2}$ & baffle spacing \\
\hline$X_{3}$ & FAME:TMP molar ratio \\
\hline$X_{4}$ & catalyst loading \\
\hline$X_{i}$ & independent variable \\
\hline$X_{j}$ & independent variable \\
\hline$Y$ & response \\
\hline$Y_{1}$ & reaction yield \\
\hline$Y_{2}$ & power \\
\hline \multicolumn{2}{|c|}{ Greek symbols } \\
\hline$\varepsilon$ & modeling error \\
\hline$\lambda$ & regression coefficient \\
\hline \multicolumn{2}{|c|}{ Abbreviations } \\
\hline ANOVA & analysis of variance \\
\hline $\mathrm{BBD}$ & box-Behnken design \\
\hline $\mathrm{CCD}$ & central composite design \\
\hline $\mathrm{DE}$ & diester \\
\hline FAME & fatty acid methyl ester \\
\hline FFA & free fatty acid \\
\hline GHG & greenhouse gas \\
\hline HOVO & high oleic vegetable oils \\
\hline IEA & international energy agency \\
\hline
\end{tabular}




\begin{tabular}{|ll|}
\hline INSF & Iranian national science foundation \\
NMR & nuclear magnetic resonance \\
OFAT & oscillatory baffled reactor \\
RSM & response surface methodology \\
TE & triester \\
TFATE & trimethylolpropane fatty acid triester \\
TMP & trimethylolpropane \\
TMU & Tarbiat Modares University \\
VG & viscosity grade \\
VI & viscosity index \\
WCO & waste cooking oils \\
\hline
\end{tabular}

\section{Acknowledgment}

The authors acknowledge the Iranian National Science Foundation (INSF) (95822653) for financial support. They also thank colleagues from TMU Renewable Energies Research Institute and the Laboratoire de Génie Chimique, Université de Toulouse who provided insight and expertise that greatly assisted this research.

\section{References}

[1] Global Market for Lubricating Oils and Greases to Reach 10.9 Billion Gallons by 2017, According to New Report by Global Industry Analysts, Inc. 2012. http://www.prweb.com/releases/lubricatingoils/lubricants reases/prweb9351336.htm (accessed November 1, 2017).

[2] Garcés R, Martínez-Force E, Salas JJ. Vegetable oil basestocks for lubricants. Grasas y Aceites 2011;62:21-8. doi:10.3989/gya.045210. 
[3] Mang T. Lubricants and their Market. Lubr Lubr Second Ed 2007:1-6. doi:10.1002/9783527610341.ch1.

[4] Honary LAT, Richter E. Biobased Lubricants and Greases: Technology and Products. vol. 17. John Wiley \& Sons; 2011. doi:10.1002/9780470971956.

[5] Bart J. Bremmer, Plonsker DL. Biobased Lubricants. Surfactants Tribol Vol 2 2011:266-7. doi:10.1201/b10868-15.

[6] Panchal TM, Patel A, Chauhan DD, Thomas M, Patel J V. A methodological review on bio-lubricants from vegetable oil based resources. Renew Sustain Energy Rev 2017;70:65-70. doi:10.1016/j.rser.2016.11.105.

[7] Syahir AZ, Zulkifli NWM, Masjuki HH, Kalam MA, Alabdulkarem A, Gulzar $\mathrm{M}$, et al. A review on bio-based lubricants and their applications. J Clean Prod 2017;168:997-1016. doi:10.1016/j.jclepro.2017.09.106.

[8] McNutt J, He Q. Development of biolubricants from vegetable oils via chemical modification. J Ind Eng Chem 2015;36:1-12. doi:10.1016/j.jiec.2016.02.008.

[9] Yunus R, Fakhru'I-Razi A, Ooi TL, Biak DRA, Iyuke SE. Kinetics of transesterification of palm-based methyl esters with trimethylolpropane. J Am Oil Chem Soc 2004;81:497-503. doi:10.1007/s11746-004-0930-7.

[10] Zaccheria F, Mariani M, Psaro R, Bondioli P, Ravasio N. Environmentally friendly lubricants through a zero waste process. Appl Catal B Environ 2016;181:581-6. doi:10.1016/j.apcatb.2015.08.032.

[11] Hajjari M, Tabatabaei M, Aghbashlo M, Ghanavati H. A review on the prospects of sustainable biodiesel production: A global scenario with an emphasis on waste-oil biodiesel utilization. Renew Sustain Energy Rev 2017;72:445-64. doi:10.1016/j.rser.2017.01.034.

[12] Putra MD, Irawan C, Ristianingsih Y. A cleaner process for biodiesel production from waste cooking oil using waste materials as a heterogeneous catalyst and its kinetic study. J Clean Prod 2018. doi:10.1016/j.jclepro.2018.06.010.

[13] Reay D, Ramshaw C, Harvey A. PROCESS IDENTIFICATIÓN: Engineering for Efficiency, Sustainability and Flexibility. Elsevier/Butterworth-Heinemann; 2011.

[14] Mazubert A, Poux M, Aubin JJ. Intensified processes for FAME production from waste cooking oil: A technological review. Chem Eng J 2013;233:201-23. doi:10.1016/j.cej.2013.07.063.

[15] Abbaszaadeh A, Ghobadian B, Omidkhah MR, Najafi G, Mayvan AA, Ghobadian B, et al. Current Biodiesel Production Technologies : a Comparative 
Review. Energy Convers Manag 2011;63:138-48.

doi:10.1016/j.enconman.2012.02.027.

[16] Ni X, Bennett DC, Symes KC, Grey BD. Inverse phase suspension polymerization of acrylamide in a batch oscillatory baffled reactor. J Appl Polym Sci 2000;76:1669-76. doi:10.1002/(SICI)10974628(20000613)76:11<1669::AID-APP8>3.0.CO;2-5.

[17] Brown CJ, Adelakun JA, Ni X wei. Characterization and modelling of antisolvent crystallization of salicylic acid in a continuous oscillatory baffled crystallizer. Chem Eng Process Process Intensif 2015;97:180-6. doi:10.1016/j.cep.2015.04.012.

[18] McLachlan H, Ni XW. On the effect of added impurity on crystal purity of urea in an oscillatory baffled crystallizer and a stirred tank crystallizer. J Cryst Growth 2016;442:81-8. doi:10.1016/j.jcrysgro.2016.03.001.

[19] Phan AN, Harvey AP, Rawcliffe M. Continuous screening of base-catalysed biodiesel production using New designs of mesoscale oscillatory baffled reactors. Fuel Process Technol 2011;92:1560-7. doi:10.1016/j.fuproc.2011.03.022.

[20] Harvey AP, Mackley MR, Seliger T. Process intensification of biodiesel production using a continuous oscillatory flow reactor. J Chem Technol Biotechnol 2003;78:338-41. doi:10.1002/jctb.782.

[21] Lucas MS, Reis NM, Li Puma G. Intensification of ozonation processes in a novel, compact, multi-orifice oscillatory baffled column. Chem Eng J 2016;296:335-9. doi:10.1016/j.cej.2016.03.050.

[22] Al-Abduly A, Christensen P, Harvey A, Zahng K. Characterization and optimization of an oscillatory baffled reactor (OBR) for ozone -water mass transfer. Chem Eng Process Process Intensif 2014;84:82-9. doi:http://dx.doi.org/10.1016/j.cep.2014.03.015.

[23] Phan AN, Harvey AP. Characterisation of mesoscale oscillatory helical baffled reactor-Experimental approach. Chem Eng J 2012;180:229-36. doi:10.1016/j.cej.2011.11.018.

[24] Solano JP, Herrero R, Espín S, Phan AN, Harvey AP. Numerical study of the flow pattern and heat transfer enhancement in oscillatory baffled reactors with helical coil inserts. Chem Eng Res Des 2012;90:732-42. doi:10.1016/j.cherd.2012.03.017.

[25] Lobry E, Gourdon C, Xuereb C, Lasuye T. Liquid-liquid dispersion in co-current disc and doughnut pulsed column effect of the operating conditions, physical properties and materials parameters. Chem Eng J 2013;233:24-38. 
doi:10.1016/j.cej.2013.08.020.

[26] Charton S, Duhamet J, Borda G, Ode D. Axial dispersion in pulsed disk and doughnut columns: A unified law. Chem Eng Sci 2012;75:468-77. doi:10.1016/j.ces.2012.04.011.

[27] Reis, N, Harvey. A.P, MM. Fluid Mechanics and Design Aspects of a novel oscillatory flow screenong mesoreactor. Chem Eng Res Des 2005;83(A4):35771. doi:10.1205/cherd.03401.

[28] Smith KB, Mackley MR. An Experimental Investigation into the Scale-up of Oscillatory Flow Mixing in Baffled Tubes. Chem Eng Res Des 2006;84:100111. doi:10.1205/cherd.05054.

[29] Koh MY, Tinia TI, Idris A. Synthesis of palm based biolubricant in an oscillatory flow reactor (OFR). Ind Crops Prod 2014;52:567-74. doi:10.1016/j.indcrop.2013.10.042.

[30] Robiah Y-R, Ikuye A, Indris SE, A Ooi TL. Preparation and characterization of trimethylolpropane esters from palm kernel oil methyl esters. 2003.

[31] Hamid HA, Yunus R, Rashid U, Choong TSY, Ali S, Syam AM. Synthesis of high oleic palm oil-based trimethylolpropane esters in a vacuum operated pulsed loop reactor. Fuel 2016;166:560-6. doi:10.1016/j.fuel.2015.11.022.

[32] Ni X, Brogan G, Struthers A, Bennett DC, Wilson SF. A systematic study of the effect of geometrical parameters on mixing time in oscillatory baffled columns. Chem Eng Res Des 1998;76:635-42. doi:10.1205/026387698525162.

[33] Brunold CR, Hunns JCB, Mackley MR, Thompson JW. Experimental observations on flow patterns and energy losses for oscillatory flow in ducts containing sharp edges. Chem Eng Sci 1989;44:1227-44. doi:10.1016/00092509(89)87022-8.

[34] Ni X, Gao S. Mass transfer characteristics of a pilot pulsed baffled reactor. J Chem Technol Biotechnol 1996;65:65-71. doi:10.1002/(SICI)10974660(199601)65:1<65::AID-JCTB352>3.0.CO;2-1.

[35] Nogueira X, Taylor BJ, Gomez H, Colominas I, Mackley MR. Experimental and computational modeling of oscillatory flow within a baffled tube containing periodic-tri-orifice baffle geometries. Comput Chem Eng 2013;49:1-17. doi:10.1016/j.compchemeng.2012.09.015.

[36] Smith KB. The Scale-Up of Oscillatory Flow Mixing. PhD Thesis, Univ Cambridge 1999.

[37] Soufi MD, Ghobadian B, Najafi G, Mohammad Mousavi S, Aubin J. 
Optimizhation of methyl ester production from waste cooking oil in a batch triorifice oscillatory baffled reactor. Fuel Process Technol 2017;167:641-7. doi:10.1016/j.fuproc.2017.07.030.

[38] Nie J. Synthesis and Evaluation of Polyol Based Biolubricants From Vegetable Oils. Dep Food Bioprod Sci 2012;Master. doi:http://hdl.handle.net/10388/ETD2012-09-757.

[39] Somidi AKR, Das U, Dalai AK. One-pot synthesis of canola oil based biolubricants catalyzed by $\mathrm{MoO} 3 / \mathrm{A} 12 \mathrm{O} 3$ and process optimization study. Chem Eng J 2016;293:259-72. doi:10.1016/j.cej.2016.02.076.

[40] Khuri AI, Mukhopadhyay S. Response surface methodology. Wiley Interdiscip Rev Comput Stat 2010;2:128-49. doi:10.1002/wics.73.

[41] Sun G, Li Y, Cai Z, Teng Y, Wang Y, Reaney MJT. K 2 CO 3 -loaded hydrotalcite: A promising heterogeneous solid base catalyst for biolubricant base oil production from waste cooking oils. Appl Catal B Environ 2017;209:118-27. doi:10.1016/j.apcatb.2017.02.078.

[42] Wang E, Ma X, Tang S, Yan R, Wang Y, Riley WW, et al. Synthesis and oxidative stability of trimethylolpropane fatty acid triester as a biolubricant base oil from waste cooking oil. Biomass and Bioenergy 2014;66:371-8. doi:10.1016/j.biombioe.2014.03.022.

[43] Yunus R, Fakhru'l-Razi A, Ooi TL, Iyuke SE, Idris A. Development of Optimum Synthesis Method for Transesterification of Plam Oil Methyl Esters and Trimethylolpropane to Environmentally Acceptable Palm Oil-Based Lubricant. J Oil Palm Res 2003;15:35-41. 